\title{
Kidney Disease after Allogeneic Hematopoietic Cell Transplantation: In Search of the Truth
}

\author{
Eleni Gavriilaki Ioanna Sakellari \\ BMT Unit, Hematology Department, G. Papanicolaou Hospital, Thessaloniki, Greece
}

In a recent issue of Acta Haematologica, Sakaguchi et al. [1] retrospectively studied risk factors for acute kidney injury (AKI) and chronic kidney disease (CKD) in 144 allogeneic hematopoietic cell transplantation (alloHCT) recipients. AKI was detected in $64.9 \%$ of the patients and independently associated with age and use of 3 or more nephrotoxic drugs. In addition, AKI significantly reduced non-relapse mortality and overall survival. CKD was found in $21.9 \%$ of the patients and independently associated with disease status at transplant and the development of AKI.

Indeed, AKI has been previously documented in 20$84 \%$ of the alloHCT recipients [2]. This wide range of previously described incidences may be attributed to the heterogeneity of diagnoses and transplant strategies, the rather small studied populations and, most importantly, the lack of standardized definitions in previous studies. A recent large retrospective study of 1,057 pediatric alloHCT recipients confirmed that age, year of transplantation, donor type, sinusoidal obstruction syndrome, and acute graft-versus-host disease (GVHD) were independent risk factors for AKI that occurred in the majority of patients [3].

Similarly, CKD is also a frequent multifactorial complication after alloHCT. In most cases, it has been tradition-

karger@karger.com

(c) 2019 S. Karger AG, Basel

www.karger.com/aha

Karger! ally considered idiopathic and named "bone marrow transplantation nephropathy", "radiation nephritis", or "conditioning-associated hemolytic uremic syndrome." Recently, novel concepts of CKD pathophysiology have led to the recognition of additional risk factors for CKD development. In a previous study by our group, we retrospectively investigated the incidence and risk factors of $\mathrm{CKD}$, including nephrotoxic medications, chemoradiotherapy of conditioning, major post-transplant complications, severe infections, and GVHD. Similar to findings by Sakaguchi et al. [1], the incidence of CKD was $20.4 \%$ at a median of 6 months. Our study showed that older age, unrelated transplantation, preceded event of AKI, and chronic GVHD were independent risk factors of CKD [4].

The role of specific nephrotoxic agents is well known [5]. Beyond drug-induced nephrotoxicity, the most important aspect of kidney injury is the recognition of potential underlying syndromes that require specific management, such as transplant-associated thrombotic microangiopathy (TA-TMA) [6, 7]. It should also be noted that in these entities, creatinine or glomerular filtration rate may not be the optimal marker of renal function. Thus, proteinuria is widely recognized as a more sensitive marker and has been introduced in recent diagnostic criteria of TA-TMA [8]. 
Better understanding of the pathophysiology of kidney damage after alloHCT will facilitate not only early diagnosis but also etiological management. Recent studies of murine alloHCT models have shown that glomerular injury is a common manifestation of kidney damage after alloHCT, in addition to interstitial nephritis and tubulitis $[9,10]$. These changes are similar to those previously observed in TA-TMA [11, 12]. Similar to TA-TMA [13], complement also seems to play a role in GVHD-associated organ injury following alloHCT $[14,15]$. In a recent study, Ma et al. [16] have also confirmed that complement is involved in renal damage following alloHCT.

In conclusion, $\mathrm{AKI}$ and $\mathrm{CKD}$ are understudied in alloHCT recipients. Kidney damage seems to be an immune-mediated effect rather than drug-induced toxicity per se. Despite improvements in supportive care, larger prospective studies are warranted to determine clinical predictors and the optimal management of renal damage after alloHCT. Importantly, further studies are needed to clarify the pathophysiology and the role of complement in renal damage after alloHCT.

\section{Disclosure Statement}

The authors have no conflicts of interest to declare.

\section{Author Contributions}

E.G. and I.S. researched the literature, contributed to discussions of the content, wrote the text, and edited the manuscript before submission.

\section{References}

1 Sakaguchi M, Nakayama K, Yamaguchi H, Mii A, Shimizu A, Inai K, et al. Risk factors for acute kidney injury and chronic kidney disease following allogeneic hematopoietic stem cell transplantation for hematopoietic malignancies. Acta Haematol. DOI: 10.1159/ 000504354

2 Hingorani S. Renal Complications of Hematopoietic-Cell Transplantation. N Engl J Med. 2016 Jun;374(23):2256-67.

3 Koh K-N, Sunkara A, Kang G, Sooter A, Mulrooney DA, Triplett $B$, et al. Acute Kidney Injury in Pediatric Patients Receiving Allogeneic Hematopoietic Cell Transplantation: Incidence, Risk Factors, and Outcomes. Biol Blood Marrow Transplant. 2018;24(4):75864.

4 Sakellari I, Barbouti A, Bamichas G, Mallouri D, Kaloyannidis P, Fragidis S, et al. GVHDassociated chronic kidney disease after allogeneic haematopoietic cell transplantation. Bone Marrow Transplant. 2013 Oct;48(10): 1329-34.

5 Jensen RR, Healy RM, Ford CD, Child B, Majers J, Draper B, et al. Amlodipine and calcineurin inhibitor-induced nephrotoxicity following allogeneic hematopoietic stem cell transplant. Clin Transplant. 2019 Jul; 33(7):e13633.
6 Gavriilaki E, Gkaliagkousi E, Grigoriadis S, Anyfanti P, Douma S, Anagnostopoulos A. Hypertension in hematologic malignancies and hematopoietic cell transplantation: an emerging issue with the introduction of novel treatments. Blood Rev. 2019 May;35:51-8.

7 Gavriilaki E, Anagnostopoulos A, Mastellos DC. Complement in Thrombotic Microangiopathies: Unraveling Ariadne's Thread Into the Labyrinth of Complement Therapeutics. Front Immunol. 2019 Feb; 10:337.

8 Gavriilaki E, Sakellari I, Anagnostopoulos A, Brodsky RA. Transplant-associated thrombotic microangiopathy: opening Pandora's box. Bone Marrow Transplant. 2017 Oct; 52(10):1355-60.

9 Higo S, Shimizu A, Masuda Y, Nagasaka S, Kajimoto Y, Kanzaki G, et al. Acute graft-versus-host disease of the kidney in allogeneic rat bone marrow transplantation. PLoS One. 2014 Dec;9(12):e115399.

10 Schmid PM, Bouazzaoui A, Schmid K, Birner C, Schach C, Maier LS, et al. Acute Renal Graft-Versus-Host Disease in a Murine Model of Allogeneic Bone Marrow Transplantation. Cell Transplant. 2017 Aug;26(8):142840.

11 Changsirikulchai S, Myerson D, Guthrie KA, McDonald GB, Alpers CE, Hingorani SR. Renal thrombotic microangiopathy after hematopoietic cell transplant: role of GVHD in pathogenesis. Clin J Am Soc Nephrol. 2009 Feb;4(2):345-53.
12 Mii A, Shimizu A, Kaneko T, Fujita E, Fukui M, Fujino T, et al. Renal thrombotic microangiopathy associated with chronic graft-versus-host disease after allogeneic hematopoietic stem cell transplantation. Pathol Int. 2011 Sep;61(9):518-27.

13 Gavriilaki E, Chrysanthopoulou A, Sakellari I, Batsis I, Mallouri D, Touloumenidou T, et al. Linking Complement Activation, Coagulation, and Neutrophils in Transplant-Associated Thrombotic Microangiopathy. Thromb Haemost. 2019 Sep;119(9):1433-40.

14 Ma Q, Li D, Nurieva R, Patenia R, Bassett R, Cao W, et al. Reduced graft-versus-host disease in C3-deficient mice is associated with decreased donor Th1/Th17 differentiation. Biol Blood Marrow Transplant. 2012;18(8): 1174-81.

15 Ma Q, Li D, Carreño R, Patenia R, Tsai KY, Xydes-Smith M, et al. Complement component C3 mediates Th1/Th17 polarization in human T-cell activation and cutaneous GVHD. Bone Marrow Transplant. 2014 Jul; 49(7):972-6.

16 Ma Q, Li D, Vasquez HG, You MJ, AfsharKharghan V. Kidney Injury in Murine Models of Hematopoietic Stem Cell Transplantation. Biol Blood Marrow Transplant. 2019; 25(10):1920-4. 